\title{
Coping with Body Image Threats among College Women: The Swimsuit Problem
}

\author{
K. Alysse Bailey ${ }^{1}$, Larkin Lamarche ${ }^{1} \&$ Kimberley L. Gammage ${ }^{1}$ \\ ${ }^{1}$ Department of Kinesiology, Brock University, St. Catharines, Canada \\ Correspondence: Larkin Lamarche, Department of Kinesiology, Brock University, 500 Glenridge Avenue, St. \\ Catharines, ON., L2S 3A1, Canada. Tel: 1-905-688-5550 x 5012. E-mail: llamarche@brocku.ca
}

Received: January 13, 2014

Accepted: February 20, $2014 \quad$ Online Published: May 20, 2014

doi:10.5539/ijps.v6n2p19

URL: http://dx.doi.org/10.5539/ijps.v6n2p19

\begin{abstract}
This study explored college women's $(N=104)$ strategies for coping with a high- and low-social-evaluative body image threat. Using an experimental design, participants read and imagined themselves in one of two scenarios: a high-social-evaluative body image threat condition (modeling a swimsuit in front of friends) or a low-social-evaluative body image threat condition (modeling a swimsuit alone) and described strategies for managing these situations. An inductive and deductive thematic approach was used to analyze the written responses. In order of frequency, the following themes were found for the high-social-evaluative threat condition: avoidance, appeasement, positive rational acceptance, social support, and social comparison. In order of frequency for the low-social-evaluative condition the following themes were found: appeasement, positive rational acceptance, avoidance, social support, outsider's opinion, and social comparison. Overall, maladaptive strategies for managing body image stressors (avoidance and appeasement) were reported the most frequently across conditions.
\end{abstract}

Keywords: adaptive/maladaptive coping, social self-preservation theory, body image stressor, social evaluation

\section{Introduction}

Many young women experience situations where their body image may be at risk. For example, situations where women's bodies are exposed, such as wearing a bathing suit in front of others, are the most uncomfortable when it comes to body image (Lamarche, Kerr, Faulkner, Gammage, \& Klentrou, 2012). Furthermore, being in an uncomfortable situation (e.g., wearing a bathing suit) has been linked to increased body shame and self-objectification, which is associated with dietary restraint and decreased math performance among women (Fredrickson, Roberts, Noll, Quinn, \& Twenge, 1998).

One theory that may help us understand what occurs during these types of situations is social self-preservation theory (SSPT; Dickerson, Gruenewald, \& Kemeny, 2004). According to SSPT, in situations where we are worried about receiving a negative evaluation from other people (i.e., social-evaluative threats), we respond both psychologically (e.g., shame) and physiologically (e.g., cortisol). It is believed that these responses (i.e., shame and cortisol) serve as a warning that one's social standing is at risk and help to prepare the body to utilize strategies such as disengagement, withdrawal, appeasement, or submission in order to prevent a further loss in social standing (Dickerson, 2008).

Most research framed within SSPT has investigated only those immediate psychobiological responses to a performance-based social-evaluative threat (i.e., the Trier Social Stress Test; Kirschbaum, Pirke, \& Hellhammer, 1993). Recent evidence suggests that SSPT may also be applicable to social-evaluative threats related to the body (Lamarche et al., 2012; Lamarche, Gammage, Kerr, Faulkner, \& Klentrou, in press; Martin, Strong, Arent, \& Bray, 2012). Using a qualitative approach, Lamarche et al. (2012) explored women's thoughts and feelings to situations that increase body image concerns and the context of those situations. Using a thematic analysis, these authors found that the thoughts and feelings described by participants were consistent with SSPT. One of the most threatening body image situations for women was being seen in a swimsuit by other people. Using a quantitative approach, Martin et al. (2012) investigated if the social evaluation of one's physique elicited a cortisol response consistent with SSPT across two separate experiments. In Study 1, participants believed they would be either exercising in a public, mirrored facility while wearing revealing clothing and being videotaped by a man (high social-evaluative threat) or exercising in a private room wearing baggy clothing and not being 
videotaped (low social-evaluative threat). In Study 2, participants were told either they would try on exercise attire and then be videotaped by a man so that a panel of judges could later evaluate the fit of the clothing (high social-evaluative threat) or they would try on exercise attire but no one else would see them (low social-evaluative threat). These authors found cortisol was higher in the high social-evaluative body image threat groups compared to the low social-evaluative threat conditions in both studies. Together, these studies exemplify how social evaluation of the body can be a major stressor, consistent with SSPT.

To date, research framed within SSPT has examined only the immediate psychobiological responses to social-evaluative threats with little attention given to the coping strategies designed to prevent a further loss in social standing outlined by the theory. Coping refers to emotional, behavioural, and cognitive adaptations to manage a situation perceived as potentially harmful (Folkman \& Lazarus, 1988; Lazarus \& Folkman, 1984). These researchers have distinguished between problem-focused coping (in which people attempt to manage the source of stress) and emotion-focused coping (in which the emotional responses to stress are managed; Folkman \& Lazarus, 1988; Lazarus \& Folkman, 1984). In the body image literature, coping strategies have been categorized as either adaptive or maladaptive in nature depending on the intention of use and the context of the situation. Cash, Santos, and Williams (2005) developed the Body Image Coping Strategies Inventory to assess coping strategies specifically related to body image and highlighted both adaptive and maladaptive strategies. They reported three coping strategies used by college men and women: avoidance (attempts to evade threats to one's body image), appearance fixing (efforts to change one's appearance), and positive rational acceptance (emphasis on the use of positive self-care or rational self-talk). They found a more favourable quality-of-life was associated with less avoidant coping and greater positive rational acceptance strategies. For women, all three types of coping strategies contributed to the prediction of disturbed eating attitudes and behaviours.

In a qualitative study, Smith-Jackson, Reel, and Thackeray (2011) analyzed interviews with college women about strategies for dealing with situations in which they felt badly about their bodies. These strategies were: exercise and healthy eating, changing appearance or shopping, social interaction, spirituality/religion, social isolation, getting out, and self-acceptance. In this sample, avoidance coping and appearance fixing strategies were reported most often. In another qualitative study, Sabiston, Sedgwick, Crocker, Kowalski, and Mack (2007) interviewed adolescent girls and found that participants used behavioural and cognitive strategies such as avoidance, appearance management, physical activity, deflection, comparison to others, and social support networks to manage situations characterized by social physique anxiety. A study by Kowalski, Mack, Crocker, Niefer, and Fleming (2006) investigated written responses from adolescent girls and boys on how they coped with a self-identified situation thought to elicit social physique anxiety. Similar to Sabiston et al. (2007) they found behavioural avoidance, short-term appearance management, social support, cognitive avoidance, and acceptance were the most frequent coping strategies reported.

\subsection{Purpose and Rationale}

Other than the research described above, the body image coping literature is limited. Thus far, the majority of the literature on body image coping has focused on the development and validation of the Body Image Coping Strategies Inventory (Cash et al., 2005) or has examined coping strategies in response to participant-identified situations primarily in adolescents (i.e., Kowalski et al., 2006; Sabiston et al., 2007). Identifying coping strategies to a specific type of body image threat, whereby participants are provided with a body image threat by the researcher, have yet to be experimentally investigated within the body image literature. Examining body image coping among college women may be important, as college has been described by researchers as "breeding grounds" for body image concerns (Striegel-Moore \& Franko, 2002, p. 189). Further, it is unclear whether contextual factors (i.e., the presence of social-evaluative threat) are related to specific types of coping strategies (i.e., maladaptive versus adaptive), a limitation to current research addressed by the present study through the use of an experimental design. Finally, to our knowledge, coping strategies outlined by SSPT, such as disengagement, withdrawal, appeasement, or submission, to social-evaluative threats have yet to be investigated in any domain. Investigating coping with a social-evaluative body image threat using an experimental design may provide one way to evaluate this contention of SSPT. Therefore, the present study investigated the types of coping strategies college women reported they would use during a high social-evaluative (HIGH-SET) body image threat (imagining modeling a bathing suit in front of three friends) and a low social-evaluative (LOW-SET) body image threat (imagining modeling a bathing suit alone) to provide a context for researchers to investigate this aspect of SSPT. Specifically, the purpose of the present study was (1) to examine what coping strategies women would report using when imagining themselves in a situation characterized by HIGH-SET versus LOW-SET; and (2) to examine whether body image coping strategies differed between HIGH-SET and LOW-SET. 


\section{Method}

\subsection{Participants}

Participants were 104 female students from a Canadian university. Exclusion criteria included (self-reported) diagnosis of or treatment for an eating disorder and varsity athletes in order to generalize to the typical female college student. The sample had a mean age of 20.42 years $(S D=2.85)$, mean height of 64.97 inches $(S D=3.08)$, mean weight of $140.21 \mathrm{lbs}(S D=22.03)$, and a mean body mass index of $23.34(S D=3.30)$. Primarily the sample identified as being Caucasian $(n=89)$ followed by African Canadian $(n=4)$ with the remaining participants self-reporting various backgrounds such as Indian, Chinese, Persian, and Muslim $(n=11)$. In addition, most students were enrolled in kinesiology/physical education as their major $(n=69)$ followed by education $(n=12)$, health science $(n=6)$, and other majors $(n=17)$. Most participants were in their second year of studies $(n=59)$, followed by fourth year $(n=18)$, then third year $(n=13)$, and other $(n=13)$, with one participant who did not report her year in school.

\subsection{Study Design and Procedures}

Upon university ethics clearance, participants were recruited through announcements made in classes and by posters placed around campus. Data were collected as part of a larger study examining psychological and heart rate responses to an imagined social-evaluative body image threat in women. Interested participants contacted a member of the research team (first author). After indicating interest, participants were provided with a letter of invitation via email and study requirements were described. Participants who were eligible scheduled a time for participation. All testing took place in a private laboratory on a university campus. All participants provided informed consent and then completed a demographic questionnaire. Then, participants were asked to read one of two scenarios (see Appendix) which were randomly assigned. The scenarios were based on a situation that has been shown to elicit negative self-evaluative states (i.e., shame; Frederick, Peplau, \& Lever, 2006; Fredrickson et al., 1998) and on qualitative work examining contextual factors increasing the perceptions of social-evaluative threats in college women (Lamarche et al., 2012). Immediately prior to and following reading the scenario, participants completed the state social physique anxiety questionnaire (see below) as a manipulation check to examine whether the conditions varied in the amount of social-evaluative threat. Next, participants were asked to respond separately to two open-ended questions based on the scenario they had just read. Participants were offered the opportunity to enter a draw to win one of ten $\$ 20$ gift cards for participation. At the conclusion of the study, participants were debriefed verbally and in writing.

\subsection{Materials}

\subsubsection{Demographics}

Participants were asked to fill out a self-reported demographic form asking questions with regards to their age, height, weight, ethnicity, and year in school.

\subsubsection{Scenarios}

Participants were provided with a scenario to read based on the social-evaluative threat identified from previous quantitative (Martin et al., 2012) and qualitative (Lamarche et al., 2012) research. Participants were asked to read the scenario carefully and imagine themselves actually experiencing the situation described: (1) trying on a swimsuit alone (LOW-SET) or (2) modeling a swimsuit in front of friends (HIGH-SET). The scenario descriptions as they appeared to participants can be found in the Appendix.

\subsubsection{State Social Physique Anxiety}

State social physique anxiety was measured with the 9-item state version of the Social Physique Anxiety Scale (Kruisselbrink et al., 2004). Participants were asked to respond to each item with how they were feeling at this moment from 1 (not at all characteristic of me) to 5 (extremely characteristic of me), with higher values representing higher state social physique anxiety. Consistent with Martin Ginis et al. (2012), this measure was used as a manipulation check to assess whether the conditions varied in the amount of perceived social-evaluative threat. This measure has showed evidence of validity and reliability in female university students (Kruisselbrink et al., 2004; Martin, Murru, Conlin, \& Strong, 2011). Internal consistency for the present study was satisfactory ( $\alpha=.90$ and .94 for pre- and post-condition state social physique anxiety respectively).

\subsubsection{Open-Ended Questions}

An open-ended question response format was used to assess the coping strategies utilized by participants to manage the HIGH-SET and LOW-SET conditions for "themselves" and for "other women". Open-ended response formats have been shown to be useful in previous qualitative research examining body image coping 
(e.g., Kowalski et al., 2006) and was found useful for this project because participants were able to directly write strategies they would use rather than relying on interviews where more interpretation may be needed by the researcher. Participants were asked to (1) list all the ways they would manage the situation themselves (2) list any other things you think other women might do to manage the situation. Participants were asked to list only one strategy per space.

\subsubsection{Description of the Research Team}

At the time of the study, the lead author (Researcher A) was a 24-year-old female Master's student. She was 162 $\mathrm{cm}$ tall, weighed $123 \mathrm{lbs}$ (body mass index $=21.30$ ), and had a petite athletic build. She was a novice researcher in the area of body image and SSPT. She was the project coordinator responsible for participant recruitment, data collection and analysis. She coded $100 \%$ of the data. During conduction of the research she typically wore jeans and a long sleeve shirt. At the time of the study, researcher B (31 years of age) had research experience investigating body image and self-presentational concerns in younger and older adult populations, and the application of SSPT to body image, using both quantitative and qualitative research designs. She coded $50 \%$ of the data. At the time of the study, researcher $\mathrm{C}$ ( 42 years of age) had research expertise in body image and self-presentational concerns across the lifespan. She has experience investigating the impact of these variables on psychological states and health behaviours, using quantitative and qualitative approaches.

\subsection{Data Analysis}

Written responses from the participants were analyzed using a thematic approach. Thematic analysis is a method used for identifying, analyzing and reporting patterns or themes in the data (Braun \& Clarke, 2006). Two main steps were used: (1) the transcripts of written responses were read through carefully to try and make sense of the data and (2) the transcripts were coded using both an inductive and deductive approach. First, new themes which emerged inductively were coded. Then, deductively, themes from SSPT (Dickerson et al., 2004) and the body image coping inventory (Cash et al., 2005) were coded. In addition, content analysis was used to reveal the saliency of themes. Content analysis, according to Grbich (2007), can be used to examine textual data in order to check for patterns of words used, their frequency and relationships. Codes within each theme were counted for each condition (HIGH-SET and LOW-SET) and are displayed as a frequency count in Figures 1 and 2 including counts for "themselves" and "other women" within each subtheme.

\subsubsection{Trustworthiness and Authenticity}

To ensure trustworthiness of the findings there were two coders for this project (Lincoln \& Guba, 1985). First, 50\% of the coding was completed by the first and second authors independently. A meeting was made between the researchers to discuss any discrepancies in codes and themes. Discussion lasted until a consensus was made on all concepts. Approximately $90 \%$ of codes and themes were agreed upon between researchers A and B. In addition, the order of themes with respect to frequency of strategies identified across conditions was consistent between researchers A and B (most to least common strategies). There was only a discrepancy with one theme-social support, which was then recoded until a consensus was reached. Then, the first author coded the remaining $50 \%$ of the transcripts independently. Lastly, a final meeting was made between all three authors to discuss codes, themes, and concepts of the data and the thematic maps. There was only a discrepancy with one minor theme-social comparison. Again, discussion lasted until a consensus was made about all concepts. To maintain authenticity, participant's own words are displayed as quotes presented throughout the results to exemplify concepts.

\section{Results}

To compare if the HIGH-SET $(n=53)$ and LOW-SET $(n=51)$ groups significantly differed on age, height, weight, or body mass index, a series of independent samples $t$-tests were performed. No between-group differences were found (all $p \mathrm{~s}>.05$ ). To examine if the two scenarios differed in amount of social-evaluative threat, an ANCOVA was conducted on post-scenario state social physique anxiety, using pre-scenario state social physique anxiety as the covariate. The results revealed a significant between-group difference on post-scenario state social physique anxiety $\left(F(1,101)=5.95, p=.02, \eta_{\mathrm{p}}{ }^{2}=.06\right)$. Participants who read the HIGH-SET versus the LOW-SET scenario reported significantly higher baseline-adjusted post-condition state social physique anxiety (HIGH-SET: $M=3.24$, $S E=.09$; LOW-SET: $M=2.92, S E=.09$ ).

\subsection{Frequency of Strategies Identified by Condition}

There were several main differences in frequencies of themes between the HIGH-SET and LOW-SET conditions. For the HIGH-SET condition, the most common coping strategy suggested by participants was avoidance, followed by appeasement, then positive rational acceptance, social support and lastly social comparison. By comparison, for the LOW-SET condition, the most frequent strategy was appeasement, then positive rational 
acceptance, avoidance, then social support, outsider's opinion, and lastly social comparison. There was consistency between conditions with the saliency of subthemes for avoidance and appeasement coping (behavioural strategies were more commonly reported than cognitive strategies).

Below we have outlined the results by theme. Responses related to behavioural disengagement and withdrawal (from SSPT) were grouped together under the theme avoidance. Any statements referring to appearance fixing were placed under the theme appeasement, since fixing appearance can be understood as behaviours used to appease others by attempting to conform to the ideal. The only theme that was different between groups was titled "outsider's opinion" and it emerged only in the LOW-SET group - this difference is outlined below. Lastly, it should be noted that there was one meaningful difference found between the responses written for "other women" and "themselves" (noted under the theme of behavioural appeasement). This difference is highlighted below. For all remaining themes the codes for "other women" and "themselves" were collapsed and reported as overall frequencies in Figures 1 and 2.

\subsection{Avoidance}

Avoidance was found to be described as either behavioural or cognitive in nature. For example, eluding evaluations of their body by not going shopping or not leaving the change room represented behavioural strategies of avoidance. By comparison, deflection or using humour were understood as ways the participants would cognitively avoid the situation.

\subsubsection{Behavioural Avoidance}

Behavioural avoidance was reported with almost twice the frequency of cognitive avoidance in both conditions (see Figures 1 and 2 for frequencies). Participants frequently stated they would rather cancel the vacation, change the destination of the trip, or not go shopping for a bathing suit than try on swimsuits with their friends. For example, one woman wrote, "Go shopping on my own time" and "Not go, perhaps make an excuse that something else has come up". One participant also said, "Avoid a setting where I would have to wear a bathing suit". Another participant wrote, "Change the destination. Go to a cold place instead of a warm place" or "Give up the trip". These strategies indicate that some women would not be able to overcome the stress of bathing suit shopping and would rather cancel the trip altogether (an experience that is arguably meant to be enjoyable). Behavioural avoidance was found to be one of the most common themes that emerged from the data, confirming how challenging it is for women to face a social-evaluative body image situation, even if they are with close friends.

Another behavioural avoidance strategy suggested by the women was not leaving the change room (as if to hide in the background to have their body not fully seen). For example, one woman said, "Don't step out of the dressing room" and another woman said, "If I was at all apprehensive, I would get only one person to come in the change room with me so I didn't have to show everyone". It was common for the women to suggest they would go shopping, but use strategies to minimize body exposure to others to hide from any negative evaluations.

\subsubsection{Cognitive Avoidance}

Participants often stated they would divert attention away from their body by changing the subject in the HIGH-SET condition. For example, one participant wrote, "Bring up the pattern or colour of bathing suit rather than fit" and another participant said "I would say the bathing suit didn't fit so I wouldn't show them" or "Pick a small size if my friends did even if I am a medium". These latter two examples represent a form of deception used by the women. These quotes emphasize that women believed they would feel so uncomfortable in this situation that they would rather lie or at the very least divert attention away from their body. For example, one woman wrote, "Redirect more attention to someone else". For the women in the HIGH-SET condition, they often described they would either lie about the true size of their bathing suit or lie about already having a bathing suit to avoid scrutiny about their body. For example, one participant said, "I would take in a couple sizes to try on so my friends don't know my size" and "I would say I already have a swimsuit". In sum, these women suggested lying was a typical strategy for managing the situation. These statements represent a way for the women to preserve their social standing through the act of deception.

Another common cognitive avoidance strategy participants reported was to make a joke or make light of the situation. For example, some participants wrote, "Try to make fun of the situation if I was feeling down" and "Make jokes about the situation and my body". Another participant wrote, "Joke about my body weight and tell them I am bigger". Humour was a very common response from the participants and may be a form of cognitive deflection from feeling negatively about their body. Overall, cognitive avoidance was a strategy suggested by some participants, especially by the HIGH-SET group, to deflect attention away from their body or to cognitively avoid negative feelings caused by the situation. 


\subsection{Appeasement}

The category appeasement was also found to have two subthemes which were behavioural and cognitive in nature. These themes represented women trying to become closer to the North American thin ideal. When women described actually planning to exercise or diet to attain the ideal, these statements were classified as behavioural appeasement. This theme was found to have the highest frequency in the LOW-SET condition and the second highest in the HIGH-SET condition. When women described talking about possible activities they could do to attain the ideal, such as "wanting" to exercise, these statements were classified under the subtheme of cognitive appeasement. For both the HIGH-SET and LOW-SET conditions, cognitive appeasement was found to have a much lower frequency than behavioural appeasement (see Figures 1 and 2).

\subsubsection{Behavioural Appeasement}

The women commonly reported how they would engage in a new diet or exercise program before shopping and before the vacation. However, it is important to note that this change in diet or exercise was very short term ("Try to eat healthy for the next few weeks"). Sucking in their belly or restraining eating before shopping were also described as strategies performed to immediately deal with trying on swimsuits for those in the LOW-SET condition. One participant wrote, "Suck in my stomach so it's not as obvious for me to see" and "not eat before I go shopping so I'm not bloated". Other more immediate strategies to appease included concealing their body by purchasing a cover-up or bathing suit wrap to hide any features not in line with the ideal.

One meaningful difference between responses for "themselves" and "other women" was with strategies of behavioural appeasement. Although this was a rare occurrence, some women in both the HIGH-SET and LOW-SET conditions wrote very extreme methods they felt "other women" would use in terms of appeasement. For example, one participant said, "Not eat at all" and "Over-exercise" or "Do a tummy tuck" and "Have by-pass surgery". One participant even said, "Turn to an eating disorder". These extreme strategies were only reported as used by other women (not themselves), which may represent a misperception of the lengths to which other women are willing to go to lose weight. They were much more extreme than the behaviours women reported that they themselves would engage in before shopping or going on vacation.

\subsubsection{Cognitive Appeasement}

Statements by the women which displayed cognitive appeasement were those suggesting they would talk about losing weight (but not actually do it). For example, one participant wrote "Tell myself that I will eat healthy for the next two weeks..." or "Tell yourself there is still time to lose weight". Overall, cognitive appeasement was represented by statements suggesting the women would think or imagine the ideal without actually engaging in any behaviour to attain it.

\subsection{Positive Rational Acceptance}

Positive rational acceptance is any mental or behavioural activity that emphasizes the use of positive self-care, rational self-talk and acceptance of the body (Cash et al., 2005). Positive rational acceptance included any responses where the women would willingly take on the social-evaluative body image threat using positive self-talk or appreciating their own body. Some participants suggested they would choose only bathing suits they were comfortable with and that they knew would fit their body appropriately. For example, one participant wrote, "Buy a bathing suit I feel comfortable in" and "Use my own opinion about which bathing suit I choose". Some participants described using positive self-talk and rational thinking; for example one participant wrote, "Self motivate myself ('I look fine')" and "I would say to myself repeatedly, this is my body, this is my figure, this is my genetics! I've got to love it". Overall, the women who suggested strategies related to positive rational acceptance conveyed acceptance and comfort with their body.

\subsubsection{Attention Seeking}

Under this category we placed the subtheme "attention seeking" to highlight when women would describe wanting to flaunt or "show-off" their body. Attention seeking was not frequent enough to form a theme alone but rather belongs under positive rational acceptance as these participants exuded extreme confidence in both body image scenarios (or at least wanted to appear as though they were confident). For example, one participant wrote, "I have worked hard to get my body to the way it is so I should show it off" and "Find a bikini that emphasizes my chest/butt". These participants displayed confidence with their bodies and wanted to display their appearance to others. 


\subsection{Social Support}

Social support comprised any statements for which the women described using their friends or family members as a resource to feel better about themselves or the situation. Some women suggested bringing their mom would help ease the situation. For example, one participant wrote, "Go with my mom or sister" and "Call my mom for advice on what to buy". Other women suggested bringing anyone they knew who would provide comfort or support. For example, "Bring someone with me who will offer positive reassurance". Bringing someone who they believed would not judge their appearance was important during a stressful body image situation such as the scenario in this study.

Another important aspect of social support was trust and honesty from their friends. Many of the women stated that as long as their friends were honest about their body and they could trust their opinion, the situation was not as stressful. For example, one woman wrote, "Go with friends you trust will be honest but not rude". Another woman stated, "Allow myself to understand that these are my friends and I would rather them be honest with me than other strangers". Many of the women suggested they would confide in their friends and be honest if the situation was too uncomfortable; for instance one woman wrote, "I would tell my friends that I was not comfortable going on the trip" and "I would tell my friends that I don't feel comfortable wearing a swimsuit in front of them because I don't want to be judged". Overall, trust and honesty appeared to be important factors when dealing with a social-evaluative situation. However, even in the LOW-SET condition, participants suggested they would take a friend or their mom for comfort and support. This also emphasizes the challenge for women to evaluate their own body while bathing suit shopping.

\subsection{Social Comparison}

Social comparison was found to be a minor but unique theme in which women compared themselves to others in a way to feel better or worse about their own appearance. These women wrote that they would either negatively talk about someone else's appearance to make themselves feel better or avoid comparison all together. For example, one participant wrote, "Talk negatively about someone else's weight to make themselves feel better". Another woman wrote, "Don't try on the same suits as your friends" as if to avoid potential comparisons, or "Not try them on at the same time so not to compare". It seems that social comparison can act both as a coping strategy and as a source of negative body-related feelings. Some women indicated they would rather avoid comparing to others as that would make them more uncomfortable, however other women took comfort in comparing themselves with others.

\subsection{Outsider's Opinion}

The most interesting difference between the HIGH-SET and LOW-SET groups was that women in the LOW-SET condition stated they would seek an "outsider's opinion". Essentially, this can be understood as turning the LOW-SET condition into a HIGH-SET condition by adding in another party (i.e., an evaluator), although this conclusion should be considered in light of the manipulation check indicating that the HIGH-SET condition reported significantly higher baseline-adjusted post-scenario state social physique anxiety. This seems counterintuitive since the women in the HIGH-SET condition commonly stated they would not allow any stranger from the store see their body in a bathing suit, or report doing things that would reduce the potential for body exposure and evaluation (i.e., "Try not to come too far out of the change room so random people couldn't see me"). However, in the LOW-SET group, it was common for women to state they would rather a second opinion about the bathing suit and would often suggest they would ask the store clerk or send pictures to friends and family members. For example, one woman wrote, "Ask someone in the store for their opinion" and "They could take a picture of the bikini to show friends ..." or "Ask the associate to help you out in finding one". Some women suggested asking complete strangers in the store, such as other customers, for instance, "Ask other customers their opinion". Overall, for the LOW-SET scenario the women discussed the importance of having a second opinion about their appearance in the bathing suit. This demonstrates the importance of being accepted by others (i.e., needing approval from other people) and that women are willing to be evaluated by others (even if it can elicit negative body-related thoughts) in order to get this approval. 


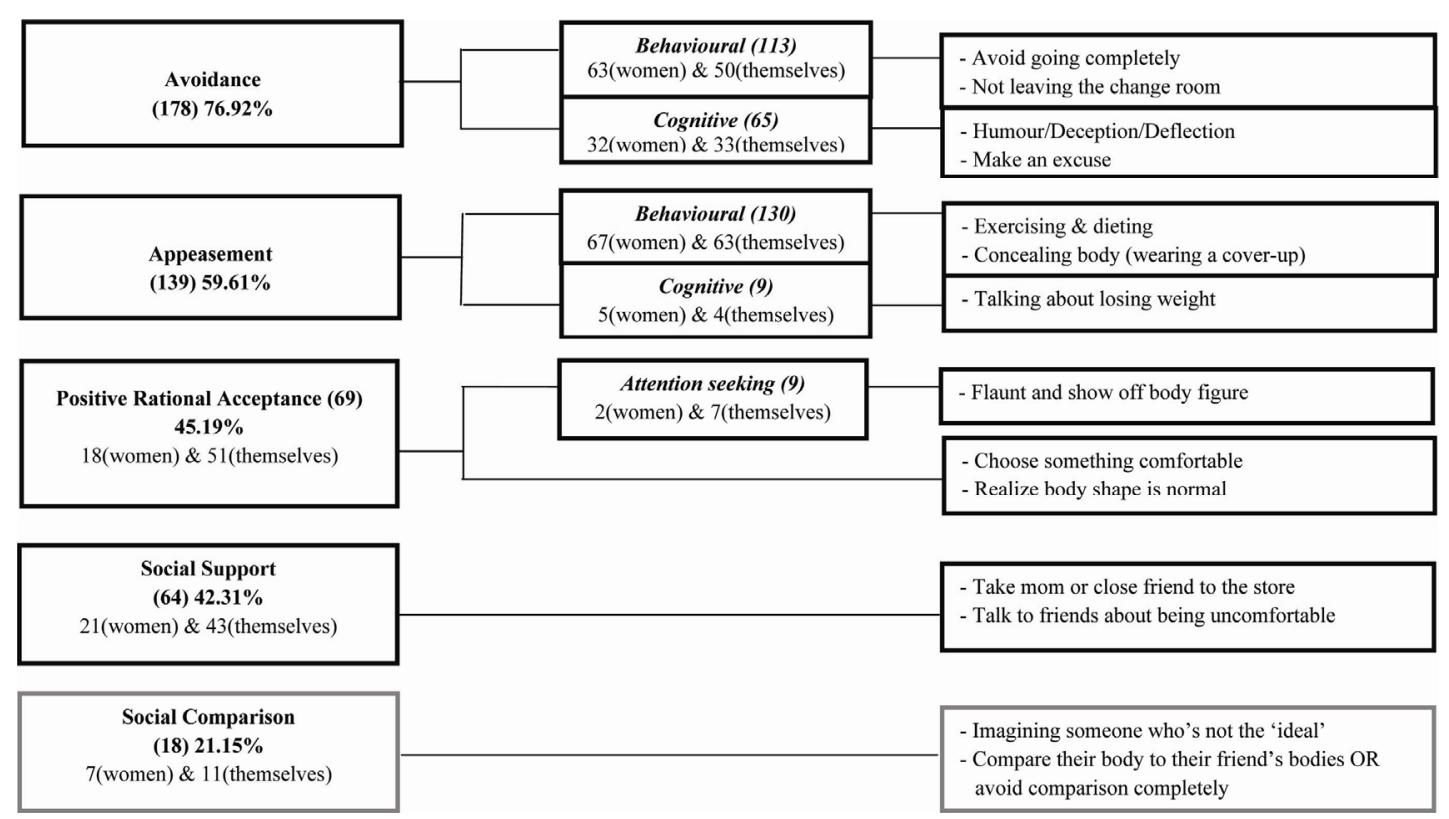

Figure 1. High-Social-Evaluative Threat

Note. Thematic map displays the themes in bold with their frequency count in brackets and percentage of participants who suggested that management strategy outside the brackets. Subthemes are displayed in bold italics. The frequencies are also displayed for the responses written for "other women" and "themselves", however these responses were collapsed.

\begin{tabular}{|c|c|c|}
\hline \multirow{2}{*}{$\begin{array}{l}\text { Appeasement } \\
\text { (130) } 67.30 \%\end{array}$} & $\begin{array}{c}\text { Behavioural (113) } \\
\text { 63(women) \& 50(themselves) }\end{array}$ & $\begin{array}{l}\text { - Exercising \& dieting } \\
\text { - Conceal body (wearing a cover-up) }\end{array}$ \\
\hline & $\begin{array}{c}\text { Cognitive (17) } \\
\text { 6(women) \& 11(themselves) }\end{array}$ & $\begin{array}{l}\text { - Stare in the mirror } \\
\text { - Talk about wanting to eat healthy/lose weight }\end{array}$ \\
\hline \multirow{2}{*}{$\begin{array}{l}\text { Positive Rational Acceptance } \\
\text { (104) 51.92\% } \\
\text { 39(women) \& 65(themselves) }\end{array}$} & \multirow{2}{*}{$\begin{array}{c}\text { Attention Seeking (1) } \\
1 \text { (women) \& 0(themselves) }\end{array}$} & - Flaunt and show-off body figure \\
\hline & & - Compliment self \& build self-confidence \\
\hline \multirow{2}{*}{$\begin{array}{l}\text { Avoidance } \\
\text { (94) } 51.92 \%\end{array}$} & $\begin{array}{c}\text { Behavioural (81) } \\
\text { 46(women) \& 35(themselves) }\end{array}$ & $\begin{array}{l}\text { - Don't leave the change room } \\
\text { - Not go on the vacation }\end{array}$ \\
\hline & $\begin{array}{c}\text { Cognitive (13) } \\
7 \text { (women) \& 6(themselves) }\end{array}$ & $\begin{array}{l}\text { - Not look in the mirror } \\
\text { - Avoid mirrors altogether }\end{array}$ \\
\hline \multirow{2}{*}{$\begin{array}{c}\text { Social Support } \\
\text { (47) } 35.57 \% \\
19 \text { (women) \& } 28 \text { (themselves) }\end{array}$} & & \\
\hline & & $\begin{array}{l}\text { - Go with a friend for support } \\
\text { - Talk to siblings/family members for support }\end{array}$ \\
\hline \multirow{2}{*}{$\begin{array}{c}\text { Outsider's Opinion } \\
\text { (38) 27.88\% } \\
24 \text { (women) \& } 14 \text { (themselves) }\end{array}$} & & \multirow{2}{*}{$\begin{array}{l}\text { - Wanting/needing another's opinion } \\
\text { - Asking store clerk's opinion }\end{array}$} \\
\hline & & \\
\hline \multirow{2}{*}{$\begin{array}{c}\text { Social Comparison } \\
\text { (5) } 9.61 \% \\
5 \text { (women) \& } 0 \text { (themselves) }\end{array}$} & & \multirow{2}{*}{$\begin{array}{l}\text { - Comparing body to other women (in positive } \& \\
\text { negative ways) }\end{array}$} \\
\hline & & \\
\hline
\end{tabular}

Figure 2. Low-Social-Evaluative Threat

Note. Thematic map displays the themes in bold with their frequency count in brackets and percentage of participants who suggested that management strategy outside the brackets. Subthemes are displayed in bold italics. The frequencies are also displayed for the responses written for "other women" and "themselves", however these responses were collapsed. 


\section{Discussion}

Overall, our findings were consistent with both SSPT and body image coping strategies described by Cash et al. (2005). The present findings provide some evidence of the applicability of SSPT with respect to coping outcomes and how it is related to body image coping strategies used among college women. According to SSPT (Dickerson et al., 2004), when we encounter social-evaluative threats (threats that may involve a negative evaluation from other people) there is both a physiological and psychological response. These responses serve as a warning that one's social status or standing is at risk, and help to prepare the body to deal with these threats (Dickerson, 2008). Social self-preservation theory hypothesizes that these psychobiological responses also reinforce appropriate behavioural responses, such as disengagement, withdrawal, and appeasement to help maintain one's social standing. Overall, women in this study were found to use strategies consistent with SSPT to cope with a social-evaluative body image threat (modeling a bathing suit in front of others). Behavioural disengagement and withdrawal from the threat were common types of responses from the women in this study and have been understood as overall avoidance coping strategies. Appeasement was another common coping response from the women and involved methods of fixing appearance. Interestingly, however, these same coping responses from SSPT were found to be used for the LOW-SET condition. There are several possible explanations for the similarities between the responses in the two conditions: (1) there is always a social-evaluative component in a body image setting (i.e., when the body is the core of a discussion or event) (2) many of the responses suggested by the women indicate that participants in the LOW-SET condition essentially turned the LOW-SET condition into a HIGH-SET (or higher) condition by adding an evaluator (e.g., store clerk).

Women encounter many situations where they feel their body image is "at risk" and adapt to these situations by utilizing specific coping strategies. However, some strategies can be understood as more adaptive than others. For example, as found by Cash et al (2005), positive rational acceptance has been identified as a more adaptive way of dealing with body image stressors. They found positive rational acceptance was associated with less dysfunction compared to avoidant and appearance fixing strategies. Women who used positive rational acceptance showed more favourable quality-of-life experiences related to their body image. Our study highlights that fewer women reported that they would use positive rational acceptance as a means to handle body image threats, particularly those with a social-evaluative component. Rather, consistent with our study, more women tend to use avoidance and appearance fixing strategies (i.e., trying to meet the ideal; Cash et al., 2005). Avoidance can be understood as a maladaptive strategy because these women may never learn how to appropriately deal with daily body image stressors. Some situations may not be always avoidable, and therefore it is necessary to learn how to deal with these situations directly.

More importantly, appeasement strategies can be understood as particularly problematic as they only validate cultural ideals and reinforce objectification of the body. Self-objectification leads to a form of self-conscious awareness characterized by vigilant monitoring of the body's physical appearance (Fredrickson et al., 1998). This in turn has been shown to be related to increased body shame, restrained eating behaviour and reduced mental performance. Interestingly in our study, women who responded to the LOW-SET scenario reported appeasement strategies as the most frequent strategy. This means that even when there is no explicit social evaluation, the most important aspect of the bathing suit shopping and going on the vacation is still meeting society's ideal. This was especially apparent as women in this group reported they would actively seek opinions from others (even strangers). This finding is interesting because the women in the LOW-SET condition consistently reported the importance of meeting the ideal even though no one else would see them in the swimsuit. It seems that looking one's best takes precedence over possible negative social evaluation. This finding can be linked to objectification theory (Fredrickson \& Roberts, 1997) as these women have made a low-social-evaluative situation into a high-social-evaluative situation as it appears they need a second "gaze" evaluating their body. Women have been socialized into believing their worth is determined by their appearance (Hesse-Biber, 2007). This belief is reflected in those women, particularly in the LOW-SET condition, who reported they would seek out evaluation of their appearance. It is possible that objectifying their body at the store is perhaps used as preparation for the evaluations they will receive on the vacation.

\subsection{Contributions of the Present Study}

The current study contributes to our knowledge of SSPT and our understanding of body image coping. While authors have speculated about the ways in which people may manage their responses to social-evaluative threats (e.g., appeasement, withdrawal, avoidance behaviours; Dickerson et al., 2004) it is unclear whether these responses do in fact occur. The present study is the first to address this issue. The most common coping responses to social-evaluative threat were in fact consistent with SSPT. This study also provides further support for the application of SSPT to understanding body image. In conjunction with previous research examining 
psychobiological responses to social-evaluative body image threats (Lamarche et al., 2012; Martin et al., 2012), this study provides further evidence that body image threats are in fact social-evaluative threats.

In terms of body image, the present study emulates some of the findings from previous research in body image coping conducted in adolescents (Kowalski et al., 2006; Sabiston et al., 2007). For example, Kowalski et al. (2006) found avoidance coping was the most common strategy used to cope with a situation high in social physique anxiety (i.e., a social-evaluative threat) among adolescent boys and girls, consistent with our findings for the HIGH-SET condition. These consistent findings with respect to maladaptive body image coping strategies across different studies and different age groups are disconcerting as it appears these maladaptive strategies used during adolescence carry over into later life (e.g., during college; Smith-Jackson et al., 2011). This emphasizes the importance of implementing programs early, such as during the elementary and high school years, to prevent the adoption of maladaptive body image coping strategies during the developing years. In addition, information about how college women cope with body image threats can aid in the development of interventions designed to teach women how to use more adaptive coping strategies.

\subsection{Limitations and Future Directions}

The current study has limitations that need to be acknowledged. First, the current findings can only be generalized to the specific body image threat used in this study. Second, the findings can only be generalized to healthy college women. It is possible that other groups cope differently with body image threats and what is understood as uncomfortable for college women may not be the case for other groups (e.g., men). It should also be noted that most of the participants were kinesiology majors and they may have a different relationship with their bodies than other students. Finally, this study relied on participants imagining how they would feel in a situation rather than having them placed in that situation. Nevertheless, results from this study demonstrate some interesting findings from simply imaging a scenario.

The current study used open-ended questions to allow participants to describe their strategies in their own words; future research could use a validated measure (e.g., Body Image Coping Strategies Inventory, Cash et al., 2005) to examine quantitatively which strategies are used to manage body image situations varying in social-evaluative threat. Other body image variables (i.e., body dissatisfaction, self-objectification) should also be investigated as potential moderators of the social-evaluative threat-coping relationship. For example, women with high body dissatisfaction may be more susceptible to social-evaluative body image threats or may use different coping strategies than women low in body dissatisfaction. Future research should explore what characterizes individuals who use more adaptive versus maladaptive coping.

Future research could examine body image coping in other populations such as people who have a physical disability, as coping can be a very important aspect of their quality-of-life. Furthermore, future studies should investigate which body image coping strategies women find effective and the reasons why they choose the strategies they do. Women use maladaptive coping strategies (i.e., avoidance) because they perceive them to be most effective at immediately relieving the stress of the situation. Finally, the effectiveness of interventions to change coping strategies should be evaluated. Finding ways to improve adaptive coping may have practical applications in clinical populations; an examination of contextual factors (i.e., amount of social evaluation) that may potentially influence whether an individual uses adaptive or maladaptive coping strategies may add to the current body image coping literature.

\section{Acknowledgements}

Funding for this project was provided by the Social Sciences and Humanities Research Council of Canada.

\section{References}

Braun, V., \& Clarke, V. (2006). Using thematic analysis in psychology. Qualitative Research in Psychology, 3, 77-101. http://dx.doi.org/10.1191/1478088706qp063oa

Cash, T. F., Santos, M. T., \& Williams, E. F. (2005). Coping with body-image threats and challenges: Validation of the Body Image Coping Strategies Inventory. Journal of Psychosomatic Research, 58, 191-199. http://dx.doi.org/10.1016/j.jpsychores.2004.07.008

Dickerson, S. S. (2008). Emotional and physiological responses to social-evaluative threat. Social \& Personality Psychology Compass, 2, 1362-1378. http://dx.doi.org/10.1111/j.1751-9004.2008.00095.x

Dickerson, S. S., Gruenewald, T. L., \& Kemeny, M. E. (2004). When the social self is threatened: Shame, $\begin{array}{llll}\text { physiology, and health. Journal of Personality, } & \text { 72, }\end{array}$ http://dx.doi.org/10.1111/j.1467-6494.2004.00295.x 
Folkman S., \& Lazarus R. S. (1988). Coping as a mediator of emotion. Journal of Personality and Social Psychology, 54, 466-475. http://dx.doi.org/10.1037/0022-3514.54.3.466

Frederick, D. A., Peplau, L. A., \& Lever, J. (2006). The swimsuit issue: Correlates of body image in a sample of 52,677 heterosexual adults. Body Image, 3, 413-419. http://dx.doi.org/10.1016/j.bodyim.2006.08.002

Fredrickson, B. L., \& Roberts, T. A. (1997). Objectification theory. Psychology of Women Quarterly, 21, 173-206. http://dx.doi.org/10.1111/j.1471-6402.1997.tb00108.x

Fredrickson, B. L., Roberts, T. A., Noll, S. M., Quinn, D. M., \& Twenge, J. M. (1998). The swimsuit becomes you: Sex differences in self-objectification, restrained eating, and math performance. Journal of Personality and Social Psychology, 75, 269-284. http://dx.doi.org/10.1037/0022-3514.75.1.269

Grbich, G. R. (2007). Analyzing Qualitative Data. London, England: Sage Publications.

Hesse-Biber, A. N. (2007). The Cult of Thinness. New York, NY: Oxford University Press.

Kirschbaum C., Pirke K. M., \& Hellhammer D. H. (1993). The "Trier Social Stress Test"-A tool for investigating psychobiological stress responses in a laboratory setting. Neuropsychobiology, 28, 76-81. http://dx.doi.org/10.1159/000119004

Kowalski, K. C., Mack, D. E., Crocker, P. R., Niefer, C. B., \& Fleming, T. L. (2006). Coping with social physique anxiety in adolescence. Journal of Adolescent Health, 39, 275.e9-275.e16. http://dx.doi.org/10.1016/j.jadohealth.2005.12.015

Kruisselbrink, L. D., Dodge, A. M., Swanburg, S. L., \& MacLeod, A. L. (2004). Influence of same-sex and mixed-sex exercise settings on the social physique anxiety and exercise intentions of males and females. Journal of Sport and Exercise Psychology, 26, 616-622.

Lamarche, L., Gammage, K. L., Kerr, G., Faulkner, G., \& Klentrou, P. (in press). Examining psychobiological responses to an anticipatory body image threat in women. Journal of Applied Biobehavioral Research.

Lamarche, L., Kerr, G., Faulkner, G., Gammage, K. L., \& Klentrou, P. (2012). A qualitative examination of body image threats using social self-preservation theory. Body Image, 9, 145-154. http://dx.doi.org/10.1016/j.bodyim.2011.10.004

Lazarus, R. S., \& Folkman, S. (1984). Stress, appraisal, and coping. New York, NY: Springer Publishing Company.

Lincoln, Y. S., \& Guba, E. G. (1985). Naturalistic Inquiry. Beverly Hills, CA: Sage Publications.

Martin, G. K. A., Murru, E, Conlin, C., \& Strong, H. A. (2011). Construct validation of a state version of the social physique anxiety scale among young women. Body Image, 8, 52-57. http://dx.doi.org/10.1016/j.bodyim.2010.10.001

Martin, G. K. A., Strong, H. A., Arent, S. M., \& Bray, S. R. (2012). The effects of threatened social evaluation of the physique on cortisol activity. Psychology and Health, 27, 990-1007. http://dx.doi.org/10.1080/08870446.2011.652111

Sabiston, C. M., Sedgwick, W. A., Crocker, P. R. E., Kowalski, K. C., \& Mack, D. E. (2007). Social physique anxiety in adolescence: An exploration of influences, coping strategies, and health behaviors. Journal of Adolescent Research, 22, 78-101. http://dx.doi.org/10.1177/0743558406294628

Smith-Jackson, T., Reel, J. J., \& Thackeray, R. (2011). Coping with "bad body image days": Strategies from $\begin{array}{lllll}\text { first-year young adult college women. Body Image, } 8, & 335-342 .\end{array}$ http://dx.doi.org/10.1016/j.bodyim.2011.05.002

Striegel-Moore, R. H., \& Franko, D. L. (2002). Body image issues among girls and women. In T. F. Cash, \& T. Pruzinsky (Eds.), Body image: A handbook of theory, research, \& clinical practice (pp. 183-191). New York, NY: The Guildford Press.

\section{Appendix}

\section{Scenario Descriptions}

\section{Low-social-evaluative body image threat}

Spring break is 2 weeks away and you and your three girlfriends have booked a vacation to a warm destination. You are very excited to go - you have worked hard this term and feel that it's time for a break and a chance to 
relax. You have decided to go shopping for a new swimsuit at the mall by yourself. You know that this will entail shopping at multiple stores and trying on multiple swimsuits. However, since you will be by yourself, you will not have to get anyone else's opinions on how you look in each of the bathing suits. Only your own assessment will matter.

\section{High-social-evaluative body image threat}

Spring break is 2 weeks away and you and your three girlfriends have booked a vacation to a warm destination. You are very excited to go - you have worked hard this term and feel that it's time for a break and a chance to relax. Your friends have decided to go shopping for new swimsuits at the mall and have invited you to join them. You know that this will entail shopping at multiple stores and trying on multiple swimsuits. You also know that you will have to "model" the swimsuits for each other, in order to get everyone's opinions on how you look in each of the bathing suits. Your friends are very honest, and will provide you with an honest assessment of how you look in each of the bathing suits.

\section{Copyrights}

Copyright for this article is retained by the author(s), with first publication rights granted to the journal.

This is an open-access article distributed under the terms and conditions of the Creative Commons Attribution license (http://creativecommons.org/licenses/by/3.0/). 